\section{Complexity of risk determination}

T t has been known for some time that 1 the risks of morbidity and mortality associated with narcotic dependence are greater than among the general population. These risks are mitigated somewhat by enrolment in treatment (mostly methadone maintenance therapy), ${ }^{1}$ but the risk is less mutable in narcotic-dependent patients who also suffer from poverty, homelessness, depression or polysubstance abuse.

Benedikt Fischer and associates ${ }^{2}$ have correlated one particular risk experienced by illicit opioid users - the risk of overdose - with homelessness, other substance use and recent involvement in drug treatment, suggesting that prevention efforts targeting these factors are more likely to be effective.

The risks faced by an opiate-dependent patient are not static. They oscillate and may be greater during a variety of transition periods: on initiation of methadone maintenance treatment, upon discharge from treatment, at the start of a prison sentence or upon release from incarceration. However, prevention may be limited by difficulties in achieving effective collaboration between various treatment methods (methadone maintenance and drug-free treatment), as well as between institutional settings (jail and hospital).

Efforts to deal with homelessness and poverty are never an easy "sell," despite significant correlations of these situations with other problems that society deems important, such as heart disease or child abuse and neglect..$^{3-5}$ Injection drug users represent just one special interest group among many, but the other groups tend to be better organized, usually experience less stigmatization, and are more successful in fighting for both status and state funding.

In the end, the high level of risk associated with narcotic dependence rests with a variety of social, legal and medical factors. The drugs are illicit, and users must negotiate in a marketplace fraught with danger and crime. ${ }^{6}$ Furthermore, medicine has had limited success in changing the systemic determinants of risk, leaving a patient population that is highly stigmatized and marginalized by law and society.

\section{Mark Latowsky}

University of Toronto

Toronto, Ont.

\section{References}

1. Ball JC, Ross A. The effectiveness of methadone maintenance therapy. New York: Springer Verlag; 1991.
2. Fischer B, Brissette S, Brochu S, Bruneau J, el-Guebaly N, Noël L, et al. Determinants of overdose incidents among illicit opioid users in 5 Canadian cities. CMA7 2004;171(3):235-9.

3. Aday LA. At risk in America: the bealth and bealth care needs of vulnerable populations in the United States. San Francisco: Jossey-Bass; 1993

4. Cooper R, Cutler P, Desvigne-Nickens P, Fortmann SP, Friedman L, Havlik R, et al. Trends and disparities in coronary heart disease, stroke, and other cardiovascular diseases in the United States: findings of the National Conference on Cardiovascular Disease Prevention. Circulation 2000;102:3137-47.

5. Study findings: study of national incidence and prevalence of child abuse and neglect. Washington: US Department of Health and Human Services, National Institute of Child Health and Human Development, National Centre on Child Abuse and Neglect; 1988.

6. Goldstein P. The drugs/violence nexus: a tripartate conceptual framework. $\mathcal{F}$ Drug Issues 1985;21 (2):345-67.

DOI:10.1503/cmaj.1041366

\section{Definitions of pediatric obesity}

Teither the article by Patricia Can1 ning and associates ${ }^{1}$ concerning prevalence of overweight and obesity among children in Newfoundland and Labrador nor the accompanying editorial by Douglas Willms, ${ }^{2}$ noted that prevalence estimates vary according to the reference population. ${ }^{3}$ Canning and associates $^{1}$ used a classification developed by Cole and colleagues, ${ }^{4}$ who calculated body mass index (BMI) cut-off 
values for "overweight" and "obese" on the basis of height and weight measurements for about 100000 children in Brazil, Great Britain, Hong Kong, the Netherlands, Singapore and the United States. Another common reference that is used for evaluating pediatric categories of "at risk of overweight" (BMI at or above the 85 th percentile) and "overweight" (BMI at or above the 95 th percentile) is a set of growth charts developed by the US Centers for Disease Control and Prevention. ${ }^{5}$ The latter reference was derived from height and weight measurements for US children collected over several decades as part of national nutrition and health examination studies.

The Dietitians of Canada, the Canadian Paediatric Society, the College of Family Physicians of Canada and the Community Health Nurses Association of Canada ${ }^{6}$ recently recommended that the Cole and colleagues ${ }^{4}$ reference be used for group (national or international) comparisons and the CDC reference $^{5}$ be used for monitoring the growth of individual children. To our knowledge, only one study ${ }^{7}$ has compared prevalence estimates of overweight obtained with these 2 methods; given this paucity of research, the Canadian recommendations ${ }^{6}$ were based on expert opinion rather than scientific evidence.

It is important to acknowledge that height and weight data for Canadian children were not included in either reference; this lack of Canadian data is particularly relevant to the situation for Aboriginal youth. Although available data show that many Aboriginal preschool and grade-school children are overweight on the basis of a nonAboriginal reference, ${ }^{8}$ the validity of this approach has been questioned, since the growth pattern of many indigenous populations worldwide has not been studied. ${ }^{9}$

Until nationally representative data on measured height and weight (including Aboriginal children) are available, Canadian researchers and health professionals alike must rely on comparisons with references that may not be representative of our children because of our geographic, cultural or ethnic uniqueness.

\section{Geoff D.C. Ball}

Assistant Professor of Pediatrics

Director, Pediatric Obesity Program

Noreen D. Willows

Assistant Professor of Community

Nutrition

Department of Agricultural, Food

and Nutritional Science

University of Alberta

Edmonton, Alta.

\section{References}

1. Canning PM, Courage ML, Frizzell LM. Prevalence of overweight and obesity in a provincial population of Canadian preschool children. CMA7 2004;171(3):240-2

2. Willms JD. Early childhood obesity: a call for early surveillance and preventive measures [editorial]. CMA7 2004;171(3):243-4.

3. Ball GDC, McCargar LJ. Childhood obesity in Canada: a review of prevalence estimates and risk factors for cardiovascular diseases and type 2 diabetes. Can 7 Appl Physiol 2003;28:117-40.

4. Cole TJ, Bellizzi MC, Flegal KM, Dietz WH. Establishing a standard definition for child overweight and obesity worldwide: international survey. BM7 2000;320:1240-3

5. Centers for Disease Control and Prevention. CDC growth charts. Atlanta: Department of Health and Human Services, National Center for Health Statistics; 2000. Report no. 314.

6. Dieticians of Canada; Canadian Paediatric Society; College of Family Physicians of Canada; Community Health Nurses Association of Canada. The use of growth charts for assessing and monitoring growth in Canadian infants and children [public policy statement]. Can $\mathcal{F}$ Diet Pract Res 2004;65:22-32.

7. Flegal KM, Ogden CL, Wei R, Kuczmarski RL, Johnson CL. Prevalence of overweight in US children: comparison of US growth charts from the Centers for Disease Control and Prevention with other reference values for body mass index. Am 7 Clin Nutr 2001;73(6):1086-93.

8. Willows N. Overweight in Aboriginal children: prevalence, implications and solutions. 7 Aboriginal Health. In press.

9. Ulijaszek SJ. Ethnic differences in patterns of human growth in stature. In: Martorell R, Haschke F, editors. Nutrition and growth. Philadelphia: Lippincott-Williams and Wilkins; 2001. p. 1-20.

DOI:10.1503/cmaj.1041328

\section{[The authors respond:]}

$W^{c}$ e agree with Geoff Ball and Noreen Willows that Canadian reference data are needed to accurately estimate the current prevalence of overweight and obesity. Unfortunately, standardized reference data based on measured heights and weights of Canadian children are not available. We calculated prevalence in our study population ${ }^{1}$ using the methods of both Cole and colleagues ${ }^{2}$ (the International Obesity Task Force) and the CDC. ${ }^{3}$ To make the data more amenable for international comparisons, an editorial decision was made to report the prevalence estimates only in terms of the first method. Fig. 1 of this letter compares the prevalence rates as estimated by the 2 methods. Six points are noteworthy.

First, the prevalence estimates for overweight (termed "at risk for overweight" by the CDC) and obesity (termed "overweight" by the CDC) were high regardless of which method was used. Also, the analysis indicated no significant difference between boys and girls in the prevalence of overweight or obesity as estimated by either method. Third, there were no differences between age groups with either method. Fourth, the CDC method yielded significantly higher rates of overweight and obesity (combined), although this difference appears to be accounted for more by the difference in estimates of obesity (18.0\% v. $8.0 \%$ ) than by the difference in estimates of overweight $(18.8 \% \mathrm{v}$. $17.6 \%)$. Further analysis indicated that a child was more than twice as likely to be classified as obese by the CDC method than by the method of Cole and colleagues. Finally, comparisons between the 2 methods with categorical modelling procedures indicated that they classified boys and girls differently. Boys were 2.85 times more likely to be classified as obese by the CDC method than by the method of Cole and colleagues, whereas girls were 2.20 more likely to be classified as obese by the CDC method.

Clearly, care must be taken in making comparisons, particularly of rates of obesity, when different methods of classification have been used.

\section{Patricia M. Canning \\ Mary L. Courage \\ Lynn M. Frizzell}

Centre of Excellence for Children and

Adolescents with Special Needs

Memorial University of Newfoundland

St. John's, Nfld.

\section{References}

1. Canning PM, Courage ML, Frizzell LM. Prevalence of overweight and obesity in a provincial population of Canadian preschool children. CMA7 2004;171(3):240-2 